\title{
Video Article \\ Methods of Soil Resampling to Monitor Changes in the Chemical Concentrations of Forest Soils
}

\author{
Gregory B. Lawrence ${ }^{1}$, Ivan J. Fernandez ${ }^{2}$, Paul W. Hazlett ${ }^{3}$, Scott W. Bailey ${ }^{4}$, Donald S. Ross ${ }^{5}$, Thomas R. Villars ${ }^{6}$, Angelica Quintana $^{7}$, \\ Rock Ouimet ${ }^{8}$, Michael R. McHale ${ }^{1}$, Chris E. Johnson ${ }^{9}$, Russell D. Briggs ${ }^{10}$, Robert A. Colter ${ }^{11}$, Jason Siemion ${ }^{1}$, Olivia L. Bartlett $^{12}$, Olga Vargas $^{13}$, \\ Michael R. Antidormi ${ }^{1}$, Mary M. Koppers ${ }^{9}$ \\ ${ }^{1}$ New York Water Science Center, U.S. Geological Survey \\ ${ }^{2}$ School of Forest Resources, University of Maine \\ ${ }^{3}$ Natural Resources Canada, Canadian Forest Service \\ ${ }^{4}$ Northern Research Station, U.S. Forest Service \\ ${ }^{5}$ Department of Plant and Soil Science, University of Vermont \\ ${ }^{6}$ Ottauquechee NRCD, USDA Natural Resources Conservation Service \\ ${ }^{7}$ Green Mountain National Forest, U.S. Forest Service \\ ${ }^{8}$ Direction de la Recherche Forestière, Ministère du Québec \\ ${ }^{9}$ Department of Civil and Environmental Engineering, Syracuse University \\ ${ }^{10}$ Division of Environmental Science, SUNY College of Environmental Science and Forestry \\ ${ }^{11}$ White Mountain National Forest, U.S. Forest Service \\ ${ }^{12}$ Natural Resources and Earth System Sciences, University of New Hampshire \\ ${ }^{13}$ Greenwich, NY Field Office, USDA Natural Resources Conservation Service
}

Correspondence to: Gregory B. Lawrence at glawrenc@usgs.gov

URL: https://www.jove.com/video/54815

DOI: doi: $10.3791 / 54815$

Keywords: Environmental Sciences, Issue 117, soil monitoring, soil change, forest soils, repeated soil sampling, forest soil variability, soil analysis, archiving soil samples

Date Published: 11/25/2016

Citation: Lawrence, G.B., Fernandez, I.J., Hazlett, P.W., Bailey, S.W., Ross, D.S., Villars, T.R., Quintana, A., Ouimet, R., McHale, M.R., Johnson, C.E., Briggs, R.D., Colter, R.A., Siemion, J., Bartlett, O.L., Vargas, O., Antidormi, M.R., Koppers, M.M. Methods of Soil Resampling to Monitor Changes in the Chemical Concentrations of Forest Soils. J. Vis. Exp. (117), e54815, doi:10.3791/54815 (2016).

\section{Abstract}

Recent soils research has shown that important chemical soil characteristics can change in less than a decade, often the result of broad environmental changes. Repeated sampling to monitor these changes in forest soils is a relatively new practice that is not well documented in the literature and has only recently been broadly embraced by the scientific community. The objective of this protocol is therefore to synthesize the latest information on methods of soil resampling in a format that can be used to design and implement a soil monitoring program. Successful monitoring of forest soils requires that a study unit be defined within an area of forested land that can be characterized with replicate sampling locations. A resampling interval of 5 years is recommended, but if monitoring is done to evaluate a specific environmental driver, the rate of change expected in that driver should be taken into consideration. Here, we show that the sampling of the profile can be done by horizon where boundaries can be clearly identified and horizons are sufficiently thick to remove soil without contamination from horizons above or below. Otherwise, sampling can be done by depth interval. Archiving of sample for future reanalysis is a key step in avoiding analytical bias and providing the opportunity for additional analyses as new questions arise.

\section{Video Link}

The video component of this article can be found at https://www.jove.com/video/54815/

\section{Introduction}

Soil development has traditionally been viewed in terms of processes that take place over centennial to millennial time scales ${ }^{1}$. Monitoring of soils that had not been perturbed by intensive uses such as agriculture was not typically considered important for policy or management concerns on the time scale of years to decades. However, recent soils research has shown that important chemical soil characteristics can change in less than a decade, often the result of broad environmental changes driven by consequences of human activities such as air pollution and climate change ${ }^{2}$. In eastern North America, repeated soil sampling is providing valuable information on the effects of acidic deposition through records of soil change in forested settings. In an effort to support and coordinate this work, the Northeastern Soil Monitoring Cooperative (NESMC) was formed in $2007^{3}$. This paper is part of the continuing effort of the NESMC to provide information that advances the use of repeated soil sampling of forest soils as a valuable tool for monitoring our changing environment. 
Repeated sampling has been used to assess changes from experimental manipulations, but long-term monitoring of forest soils in response to environmental drivers is a relatively new practice that is not well documented in the literature and has only recently been broadly embraced by the scientific community. Past skepticism was due in large part to the view that the rate of soil change was too slow to detect in the presence of the high spatial variability (horizontal and vertical) typical of forest soils. Because the collection of soil is destructive, resampling can only be done near the original sampling location. Therefore, spatial variability within the 3-dimensional space from which samples are collected must be properly quantified to detect real changes and avoid results that are an artifact of the collection method. Furthermore, the process of soil sampling and chemical analysis creates potential sources of measurement instability that can mask changes or bias results ${ }^{4}$. Measurement instability cannot be completely removed, but can be sufficiently controlled with the proper protocols to produce results with minimal uncertainty.

\section{Designing the Soil Monitoring Study}

Soil monitoring requires that soil samples are collected repeatedly over a time interval defined by the investigator. Shorter time intervals decrease the length of time needed to statistically detect a change, but longer intervals provide more opportunity for soil changes to occur ${ }^{4}$. A resampling interval of 5 years is recommended to balance these two factors, but if monitoring is being done to evaluate a specific driver, the interval should be set based on the rate of change expected in that driver ${ }^{2}$. Successful monitoring of forest soils also requires that a study unit be defined within an area of forested land that has been selected for soil monitoring. Repeated sampling at multiple locations within the study unit is used to determine if the soil of that specific study unit has changed over time. Additional study units can be selected, but each is statistically analyzed separately to evaluate if soil changes have occurred. Statistical results of multiple study units can then be grouped for the purpose of regional analysis, as demonstrated in Lawrence et al. ${ }^{5}$. The type and size of the study unit will depend on the monitoring questions being asked and the following study design considerations. Soil sampling within the study unit can be done at random locations or on a grid to obtain replicate samples as long as the sampling is done at enough locations to characterize the areal variability of the study unit without bias ${ }^{4}$. A study unit located within a single landscape type with regard to features such as slope, hillslope position, aspect, vegetation, parent material and drainage will tend to have less areal variability than a study unit that spans more than one landscape type. Avoiding sampling bias in each collection is needed to enable the values from pits sampled in any one collection to be statistically compared to the values obtained in prior and future collections. As the size of the study unit increases, the areal variability within the study unit may also increase from factors such as vegetation or slope changes. If potential causes of variability such as these become encompassed within the study unit, additional sampling locations will be needed to characterize the possible variability in soils that may occur. Therefore, the size of the study unit needs to be determined by the investigator based on the variability of the area being considered and the project resources available for sampling and resampling efforts.

A key criterion to be considered in locating the study unit is the potential for future undesired site disturbances. There should be some level of assurance that site conditions will remain suitable for the defined monitoring objectives for several decades or more. For example, a study unit with the single objective of monitoring climate change effects should be located in an area where logging will not occur in the foreseeable future.

The methodology described herein covers the sampling of an individual study unit. Study units can be replicated within a landscape type or study units can be added to characterize additional landscape types depending on the objectives and scope of the study, including whether the study involves an experimental manipulation. An example of a soil monitoring design is illustrated in Figure 1. Within the area of interest (western Adirondack region), six study units have been located. In this case, each study unit is gridded into 25 equal-sized plots. Each plot needs to be large enough to provide a space suitable for pit excavation. In forested upland terrain of the northeastern U.S. and eastern Canada, a suitable space to excavate a pit to a depth of $1.2 \mathrm{~m}$ can generally be found within a $10 \mathrm{~m}$ by $10 \mathrm{~m}$ area. Therefore, in our example, the total area of the study unit equals 1.0 ha. Each time the study unit is sampled, a chosen number of plots are randomly selected for sampling. If five replicate plots are randomly selected for sampling on a five-year interval, the study unit could be monitored for 25 years. The area required to excavate and sample one pit will vary among landscapes and must be taken into consideration in the sampling design.

The degree of replication within a study unit and the frequency of repeated sampling will vary depending on the study unit characteristics, the questions being asked and the nature of disturbances that are anticipated. Based on soil resampling studies that have detected changes with measurements commonly used in forest soils, a resampling interval of 5 years and a minimum of 5 replicate sampling locations within each study unit are recommended. Decreasing the frequency of resampling and increasing sampling replication will strengthen the ability to detect changes. 


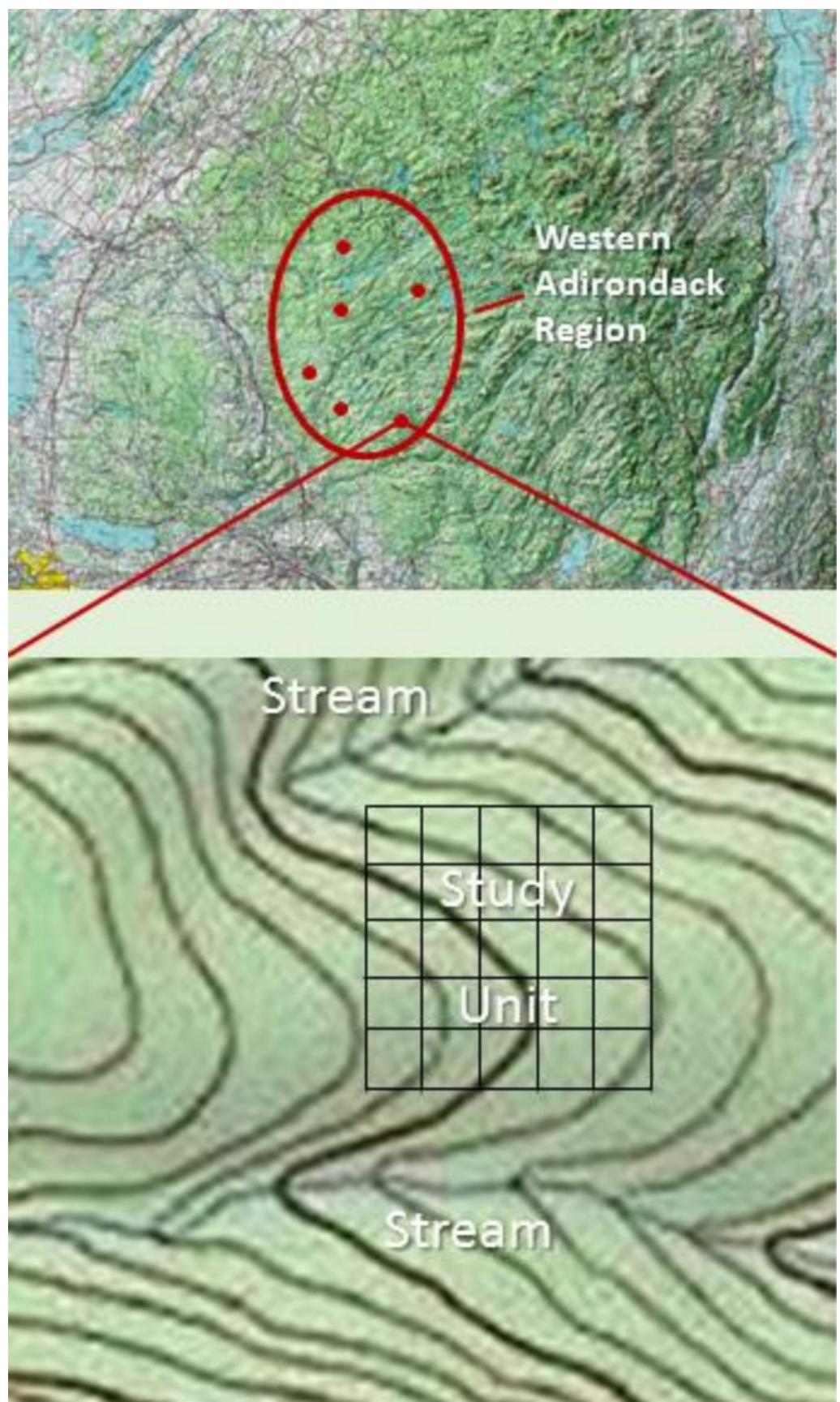

Figure 1: Example study design. A generalized resampling study design. Note that the study unit is located to avoid the riparian areas of two stream channels. Please click here to view a larger version of this figure.

\section{Soil Sample Collection - Background Information}

The collection of soil samples should be done during the season when soils tend to be dry, which most often occurs in the latter part of the growing season. By resampling at this time, consistency is also achieved with regard to plant phenology, a possible influence on soil chemical conditions. Sampling should be avoided during or immediately after heavy rains or when the soils are exceedingly wet. At least one location within the study unit should be described and documented following the USDA Natural Resource Conservation Service (NRCS) Field Book for Describing Soils ${ }^{6}$, or other appropriate protocols if following a soil classification system used outside the U.S. The field protocol provided herein follows the U.S. classification system and requires a copy of the NRCS Field Book for Describing Soils in the field. The sampler should have training and experience describing and sampling the soil type being monitored before implementing the soil monitoring protocols.

Soil collection can be done in a variety of ways, but the use of a repeatable technique is crucial to monitoring soil change. The field methodology should be recorded in a standard operating procedure (SOP). Changes in collection procedures between samplings should be avoided, but when this is not possible, all details must be documented. 
Tests should also be done to evaluate the potential for bias caused by procedural changes. Sampling can be done by horizon where (1) boundaries can be clearly identified in the field and (2) horizons are sufficiently thick to remove soil without contamination from horizons above or below. Where these criteria are not met, sampling by depth interval can be done. In any sampling, particular care must be taken to avoid mixing soil from the surface organic-rich horizon (usually $\mathrm{O}$ or $\mathrm{A}$ ) with the uppermost mineral horizon (usually $\mathrm{B}$ or $\mathrm{E}$ ). In some soils, changes in texture and color are readily visible across the organic-mineral interface, whereas in other soils color changes can be minimal so textural changes that reflect differences in organic carbon $(C)$ concentration must be relied on to identify the location of the interface. Determining this interface from textural changes can be difficult, even for experienced soil scientists. Verification of the organic-mineral interface can be done with laboratory analysis of the carbon concentration (organic horizon is defined by organic carbon concentration $>20 \%{ }^{7}$ ). In some soils, the $\mathrm{O}$ horizon can be less than $1 \mathrm{~cm}$ thick and may be too thin to sample. Sampling by both horizon and depth within the same soil profile can be effective in addressing variations in the distinctness of thicknesses of horizons within that profile. The horizons or depths to be sampled will also be dependent on the objectives of the monitoring program. Soil changes in layers closer to the surface have been more commonly identified than in deeper layers, but including deeper horizons or depth intervals can provide information that is helpful in reducing uncertainty of results. For example, in an initial sampling, a glaciated soil, heavily leached by acidic deposition, showed base saturation to be minimum in the upper $B$ horizon then increase with depth. In a repeated sampling, this pattern should also occur even if concentrations of individual layers change. If a different pattern is observed in the repeat sampling, there is a strong possibility that the two samplings were not done in comparable soil. Ideally, the sample should be collected over the full horizon thickness. However, in excessively thick horizons vertically integrating sample collection may be difficult over the entire thickness. In this situation, samples of equal volume can be collected at equally spaced intervals from the bottom to the top of the horizon. If sampling is not done over the full horizon thickness, record the sampling depth interval within that horizon.

\section{Soil Sample Processing and Analysis - Background Information}

The process of removing a soil sample from the profile alters that sample by severing roots, and causing changes in factors such as temperature, moisture, oxygen and other gas concentrations. Therefore, some measurements must be done quickly without the ability to preserve the sample, making them difficult to use in long-term monitoring programs. However, for most common physical and chemical measurements such as texture, bulk density, total $\mathrm{C}$ and nitrogen $(\mathrm{N})$, and concentrations of total and exchangeable metals, air-drying the sample after collection provides a relatively consistent method for stabilizing the chemistry before analysis. In almost all cases, soil measurements are operationally defined, reflecting both the conditions of the soil in situ, and the consequences of the sample collection, preparation, and analysis employed. Artifacts are minimized by selection of the best methods for the goals of the program, and consistency in methodology over time. Once dried, further changes in the soil sample are minimized, and with most of the moisture removed, the sample can be sieved to break up clods and remove stone and root fragments. These steps enable the sample to be homogenized prior to subsampling for chemical analysis. Just as the consistency of sample collection and processing methods must be maintained over time, potential bias from the chemical analysis must also be controlled. Documentation of the standard operating procedure (SOP) for the chemical analysis used each time samples are collected and analyzed is essential, and ideally, the same SOP is used for all sample collections. The success of the chemical analysis needs to be verified with a quality assurance program that involves the use of internal reference samples and inter-laboratory exchange samples, as well as standard internal quality control procedures. For information on comparability of commonly used chemical analysis methods see Ross et al. ${ }^{8}$.

When resampling is done over five to ten-year intervals, some changes are likely to occur in one or more aspect of the chemical analysis such as the SOP, laboratory instrumentation, laboratory personnel, or the laboratory doing the analysis. These factors create the possibility of analytical bias between the collections. To control for analytical bias, unused portions of samples from each collection should be archived for future use. Samples from the previous collection can be analyzed with the newly collected samples, and by comparing data, the possibility of analytical bias can be addressed. This approach is based on the assumption that chemical changes do not occur in the archived sample during the storage period. Loss-on-ignition and concentrations of exchangeable bases, exchangeable $\mathrm{Al}$, total $\mathrm{C}$, and total $\mathrm{N}$ have been shown to be stable in various studies that have extended up to 30 years ${ }^{9-11}$. However, storage of air-dried soils has been shown to lower soil $\mathrm{pH}^{12}$ and manganese oxides ${ }^{13}$. The mass of soil collected from each horizon or depth interval should be sufficient to complete one full set of planned chemical analyses plus additional mass for at least four sets of analyses in the future. A variety of methods have been used to archive soil samples. The method described herein follows the storage procedures used by the New York State Museum.

\section{Study Unit Selection and Description}

1. Locate a forested area with the characteristics desired for monitoring. Establish the boundaries of the study unit within this area, ensuring that (1) the study unit is representative of the area to be monitored, and (2) that the area is large enough to accommodate the planned sampling and resamplings, but not so large that an excessive amount of replicate pits are needed to represent the variability within the unit.

2. Record the location of the study unit with a global positioning system (GPS) unit. Record the center and corners if the study unit is rectangular, or center and ends of perpendicular diameters if the study unit is circular. Record written site coordinates on a field form, in addition to storing them electronically in the GPS unit. If permissible, mark key locations with permanent monuments such as an iron rod.

3. Record the slope by hanging flagging or some other marker at eye level at the study unit center and at the lowest elevation edge of study site. Measure the slope with a clinometer from (1) the highest elevation edge of the study unit to the study unit center (slope up), and (2) from the study unit center to the lowest edge (slope down). Record the compass reading along the predominant downslope direction (slope aspect) from the highest elevation edge of the study unit.

4. Record the slope position as summit, shoulder, backslope, footslope or toeslope if the study area is on a hillslope, or flat plain if the study unit is in an area of low relief. See pages 1-7 and 1-10 in Shoeneberger et al. ${ }^{6}$ to verify identification of the slope position.

5. Identify the dominant vegetation species by vertical strata. For example, record the dominant herb species in the understory below $1 \mathrm{~m}$, the dominant sapling species taller than $1 \mathrm{~m}$ but not reaching the canopy, and the dominant tree species in the canopy (those that reach the top of the canopy). How to define the strata will depend on the type of forest being worked on. Take a digital photo of the understory from the lowest elevation edge of the study unit looking upslope and from the highest elevation edge looking downslope. 
6. Select locations for pits, avoiding land surfaces that are of minor importance within the selected study unit, and therefore not representative of the study unit. Also avoid land surfaces where sampling methods are not possible because of perennial wetness, excessive rocks at or near the surface or excessive density of trees, or of a condition that is counter to the objectives of the soil monitoring project.

\section{Excavation and Profile Description}

1. Lay out a tarp (approximately $10 \mathrm{ft}$ by $12 \mathrm{ft}$ or $3.1 \mathrm{~m}$ by $3.7 \mathrm{~m}$ ) adjacent to the location where a pit is to be excavated. Choose one side of the planned pit (upslope side if possible) to protect from trampling and contamination during pit digging by covering with plastic garbage bag or something similar (Figure 2). This side will then be used for the profile description and sampling.

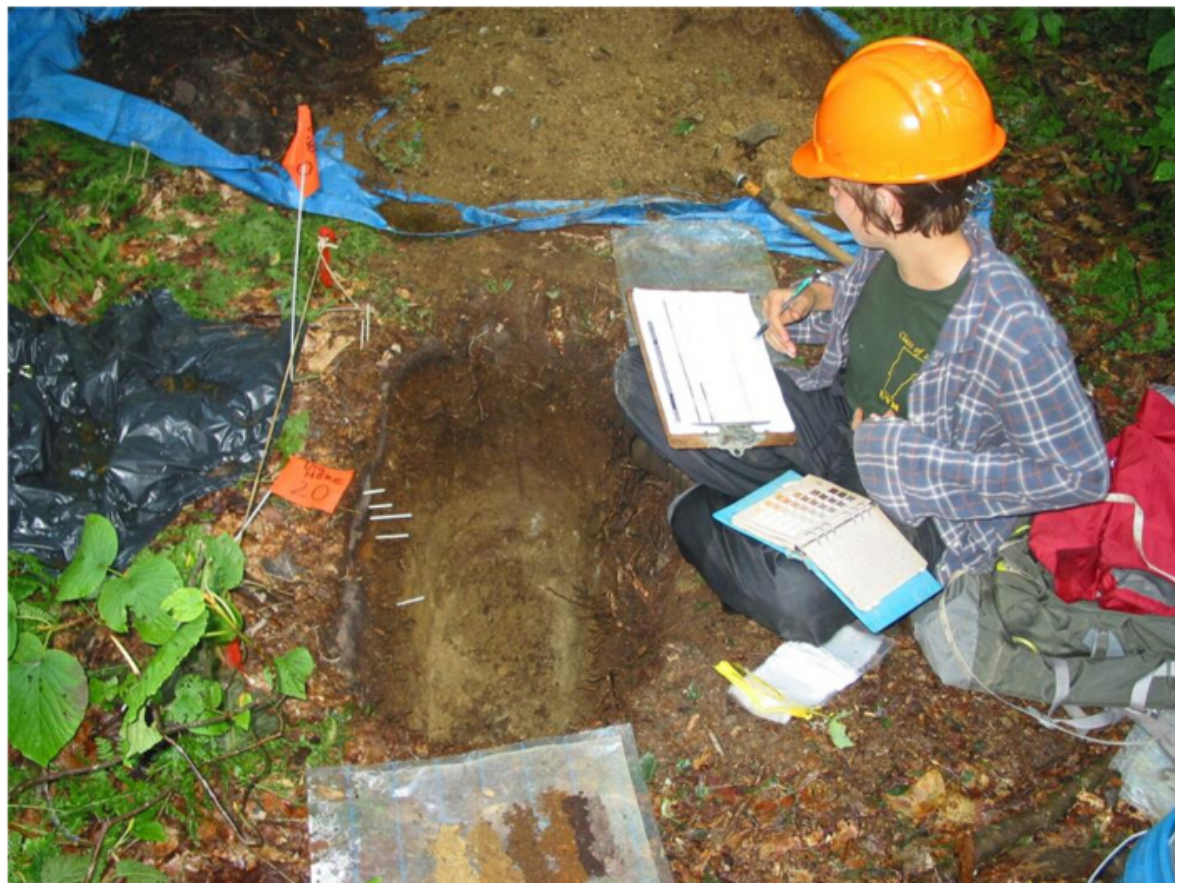

Figure 2: Completed pit excavation. Soil pit excavation showing the removed mineral soil and intact forest floor on a tarp to minimize site disturbance, along with pins marking horizons on the pit face. Please click here to view a larger version of this figure.

2. Begin excavating the pit by removing the forest floor (O horizon) with the shovel. If possible, keep the forest floor intact and place where it will not be mixed with mineral soil being removed from the pit. Excavate the pit with the smallest footprint possible (usually about 0.5 to $1 \mathrm{~m}^{2}$ ) until reaching the desired depth determined by the monitoring design.

3. Prepare a vertical pit face for description and sampling by lightly scraping downward with a hand trowel to remove any loose soil resulting from the excavation. Prune roots with hand snippers where necessary.

NOTE: If excessive rocks or roots preclude the clearing of a pit face for description and sampling, or reaching the desired depth, the pit may need to be expanded somewhat.

4. Record (in a field notebook or electronic recording device) any observations of water seeping into the pit from a pit face or the bottom of the pit.

5. Visually evaluate the pit face from top to bottom for differences in color, texture and structure. Remove small amounts of the differing soil and place side by side on a white piece of paper (such as the back side of the field form) to assist in identifying horizon boundaries, as shown in Figure 3. 


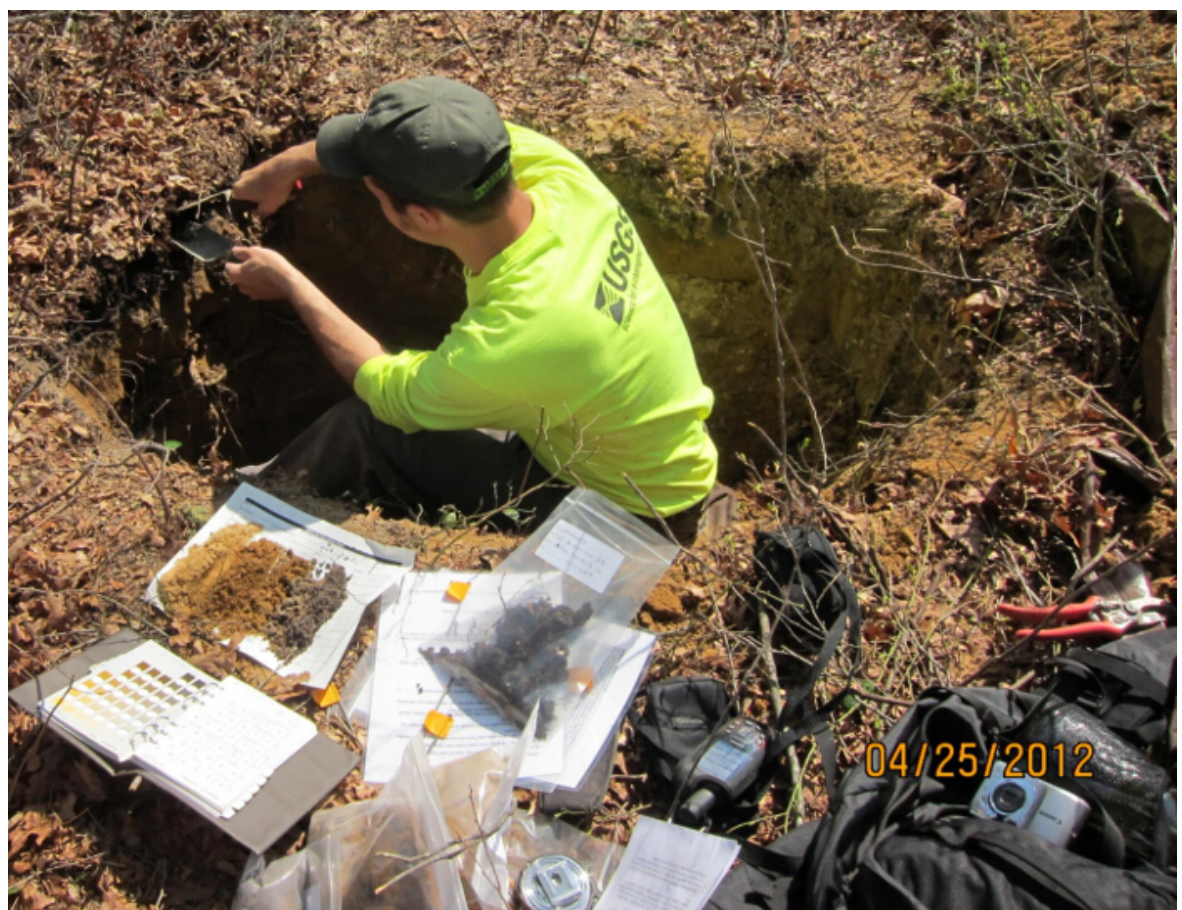

Figure 3: Sample removal technique. Technique used to remove soil from the pit face. Also shown are samples of differing colors removed from the pit face, aligned in order, to help identify horizon boundaries. Please click here to view a larger version of this figure.

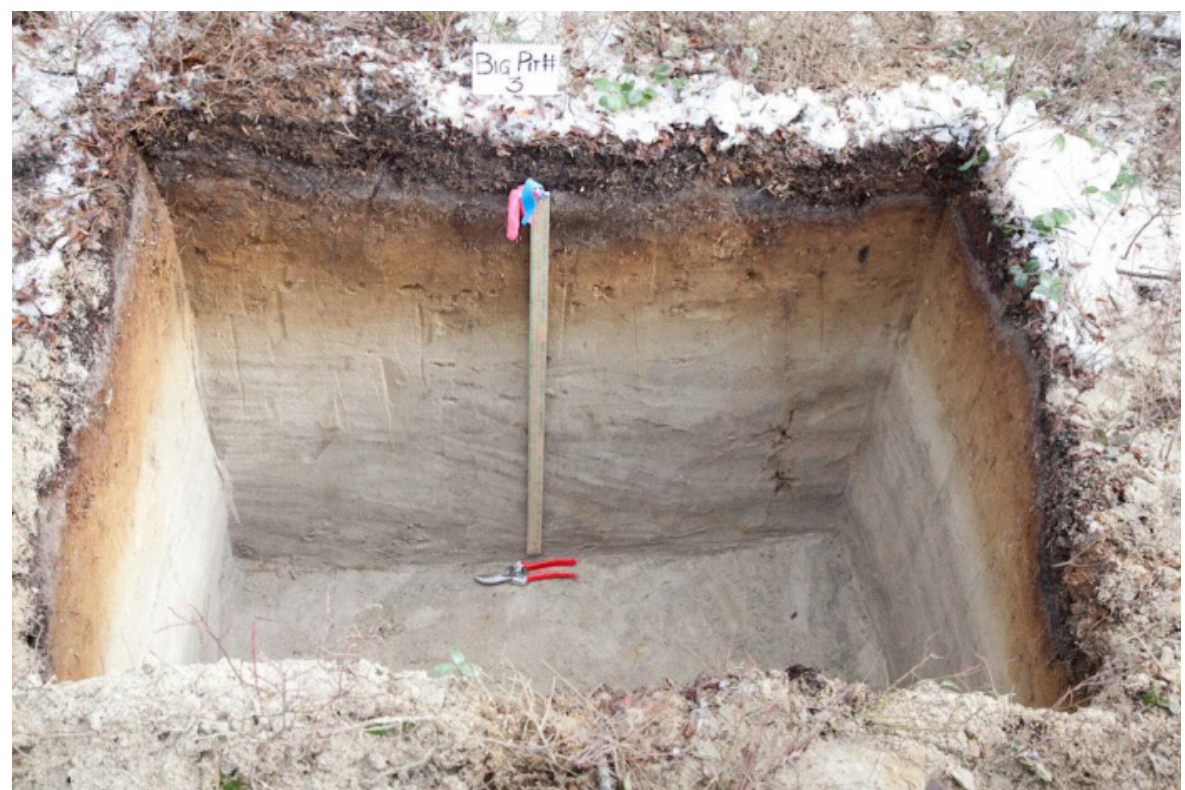

Figure 4: Example of horizon expression. A soil profile with horizon boundaries that have distinctness classes of abrupt or clear and topography that is smooth or wavy. Please click here to view a larger version of this figure. 


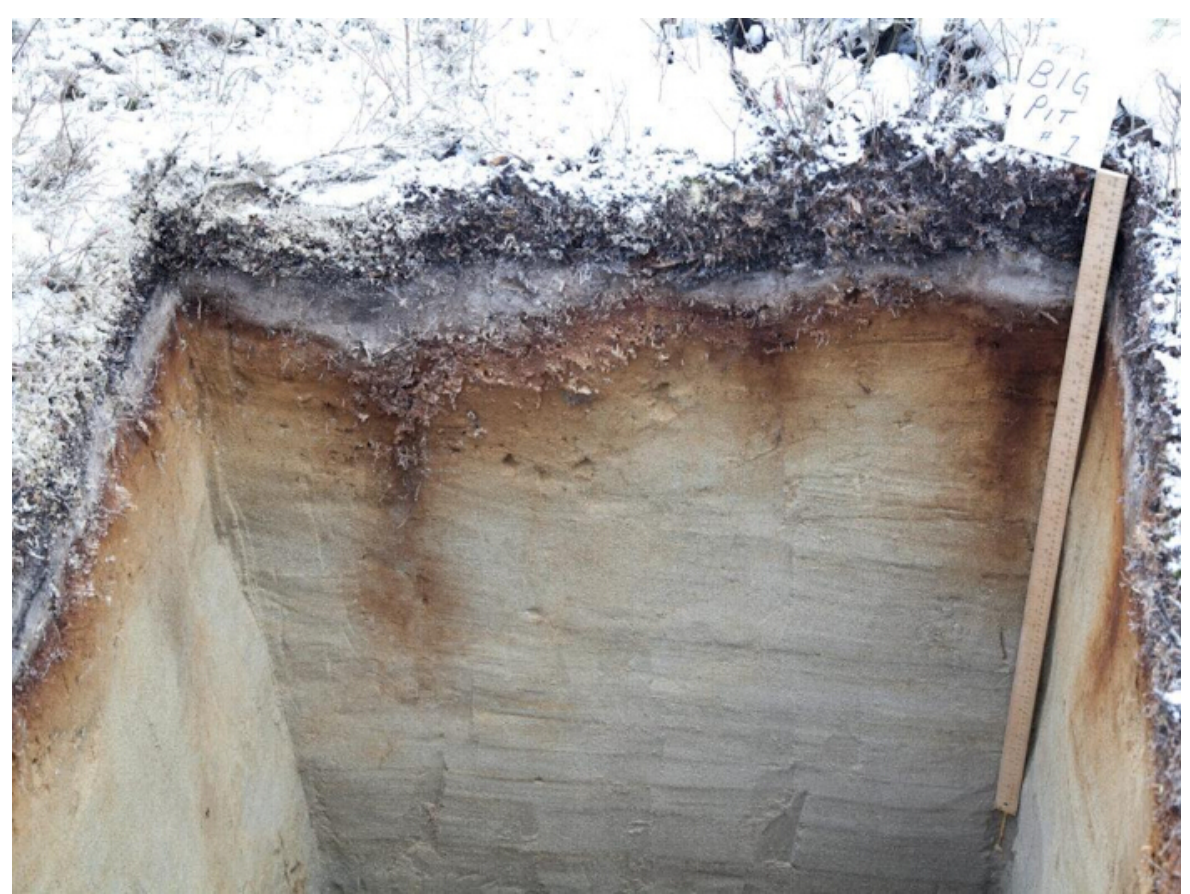

Figure 5: Example of horizon expression. A soil profile with horizon boundaries that have distinctness classes of clear or gradual and topography that is wavy or irregular. Please click here to view a larger version of this figure.

6. Record the horizon designations following pages 2-2 to $2-5$ of the NRCS Field Book ${ }^{6}$.

7. Mark horizon boundaries with T shaped pins or similar objects (Figures $\mathbf{2 , 4 , 5}$ ). Take a digital photo of the profile with horizon markers and a tape in place showing scale.

8. Measure and record the depth of the top and bottom of each horizon with a metric tape relative to the interface between the air and soil surface.

9. Record the distinctness class and topography code for the boundaries of each horizon following pages 2-6 to 2-7 of the NRCS Field Book ${ }^{6}$.

10. Record the color of each horizon using the Munsell Soil Color Book following pages 2-8 to 2-11 of the NRCS Field Book ${ }^{6}$.

11. For each horizon, record the texture class (pages 2-36 to 2-37), structure type (pages 2-52 to 2-54), and visually inspect the pit face to make a rough estimate of the quantity of rocks (as percent volume) following the instructions in the NRCS Field Book ${ }^{6}$. Also for each horizon, indicate whether fine roots ( $<2 \mathrm{~mm}$ diameter) are abundant, common, few or none.

\section{Sample Collection}

1. Select the horizons and/or depths to be sampled based on the study design and requirements.

NOTE: Collect by horizon if: (1) boundaries can be clearly identified in the field, and (2) horizons are sufficiently thick to remove soil without contamination from horizons above or below. Collect by depth interval if: (1) horizon boundaries are too thin to sample, or (2) horizon boundaries are irregular and or broken.

2. Collect the soil from the selected horizons or depth intervals, starting with the deepest sample and working upward. To remove the sample from the pit face, insert the gardening trowel near the bottom of the layer that is being sampled. Then insert a flat trowel above the gardening trowel to loosen the soil so that it can be removed with the bottom trowel (Figure 3 ).

NOTE: The mass of soil collected should equal the total mass required by the planned chemical analyses plus the mass needed for archiving (at least four additional complete analyses).

3. Place samples in sealable plastic bags and double-bag samples if soils are stony. For both horizon and depth sampling, collect soil across the breadth of the pit face where the horizon can be sampled (i.e., where the horizon is thick enough to sample and rocks and roots don't occur).

4. Label the sample bag with study unit, date, pit identification, horizon or depth interval, and sampler name.

5. Once sampling is completed, backfill the pit with the mineral soil and coarse fragments. Place forest floor on top of the mineral soil, keeping the organic material as intact as possible. Record the location of the pit with respect to the study unit monument (distance and aspect).

6. Excavate additional pits within the study unit to provide the replication called for in the sampling design. At each pit, follow steps 2.1 through 2.8 , and if profile descriptions are required at all pits, also follow steps $2-9$ through $2-11$. Then collect the samples following steps 3.1 through 3.5 .

\section{Sample Processing}

1. Within $24 \mathrm{hr}$ of collection, pour samples out of the plastic bags into pans that will facilitate air drying of the samples. Air-dry at approximately room temperature in a secure location that is protected from air-borne contaminants such as dust. Mix the samples in the pans every few days, depending on wetness. Inspect each sample for visual and tactile evidence of dryness to determine if air-drying is near completion. 
2. Verify the completion of air-drying, by weighing subsamples (approximately $5 \mathrm{~g}$ ) from several samples (a minimum of 3 ). Then oven-dry these subsamples for $24 \mathrm{hr}$ (organic soil at $60^{\circ} \mathrm{C}$; mineral soil at $105^{\circ} \mathrm{C}$ ), and reweigh. Calculate the mass of moisture lost through drying as a percent of the total mass (soil plus moisture) before drying.

3. After 2 days, repeat step 4.2 and compare the moisture lost from the first oven drying, to that lost in the second oven drying. If the moisture lost in each oven drying is within 2 percent, the soil can be considered air-dried. Once air drying is complete, place samples in plastic bags that can be sealed after expelling as much air as possible.

4. To remove coarse fragments and roots, sieve all collected soil. Pass the organic samples through a sieve with an opening of approximately 4-6 $\mathrm{mm}$; pass mineral soil samples through a sieve with an opening of $2 \mathrm{~mm}$. Additional sieving through smaller openings may be required for specific chemical analyses. For resampling, make sure that the sieving procedure matches that of the previous sampling.

CAUTION: People doing the sieving should be protected from inhaling dust either by sieving in an exhaust hood or wearing a National Institute for Occupational Safety and Health (NIOSH) approved N95 Particulate Filtering Facepiece Respirator.

\section{Chemical Analyses}

1. Choose chemical analysis methods that are consistent with those being used in similar forest soils, such as those in Ross et al. ${ }^{8}$. The U.S. Environmental Protection Agency Soil Methods Manual ${ }^{14}$ also provides a compendium of methods that continue to be commonly used for analysis of forest soils. If deviations are necessary, the data comparability must be verified. Ensure that the SOP is fully documented for each analysis.

2. Include reference soil samples with similar properties to soil samples collected in the monitoring program in all analysis batches to maintain quality control. Also include samples from inter laboratory exchanges ${ }^{8}$ to determine data comparability with other laboratories.

\section{Archiving Soil Samples}

1. Archive the soil that remains after chemical analyses for future use. Select the mass of soil to be saved on the basis of (1) how much soil was used for the full suite of measurements, (2) the anticipated number of times samples will be reanalyzed in the future, and (3) available longterm storage space.

2. With a permanent marker, write the following information on an appropriately-sized tin tie (twistable wire attached to the bag for sealing) poly lined paper bag: (1) sample identification information including horizon or depth increment, (2) sieve size, (3) date collected, and (4) any necessary laboratory information such as sample serial number.

3. Weigh and record the mass of the soil that is being archived for each sample, and place in the tin tie bag. Place the tin tie bag in an appropriately-sized plastic bag (Figure 6).

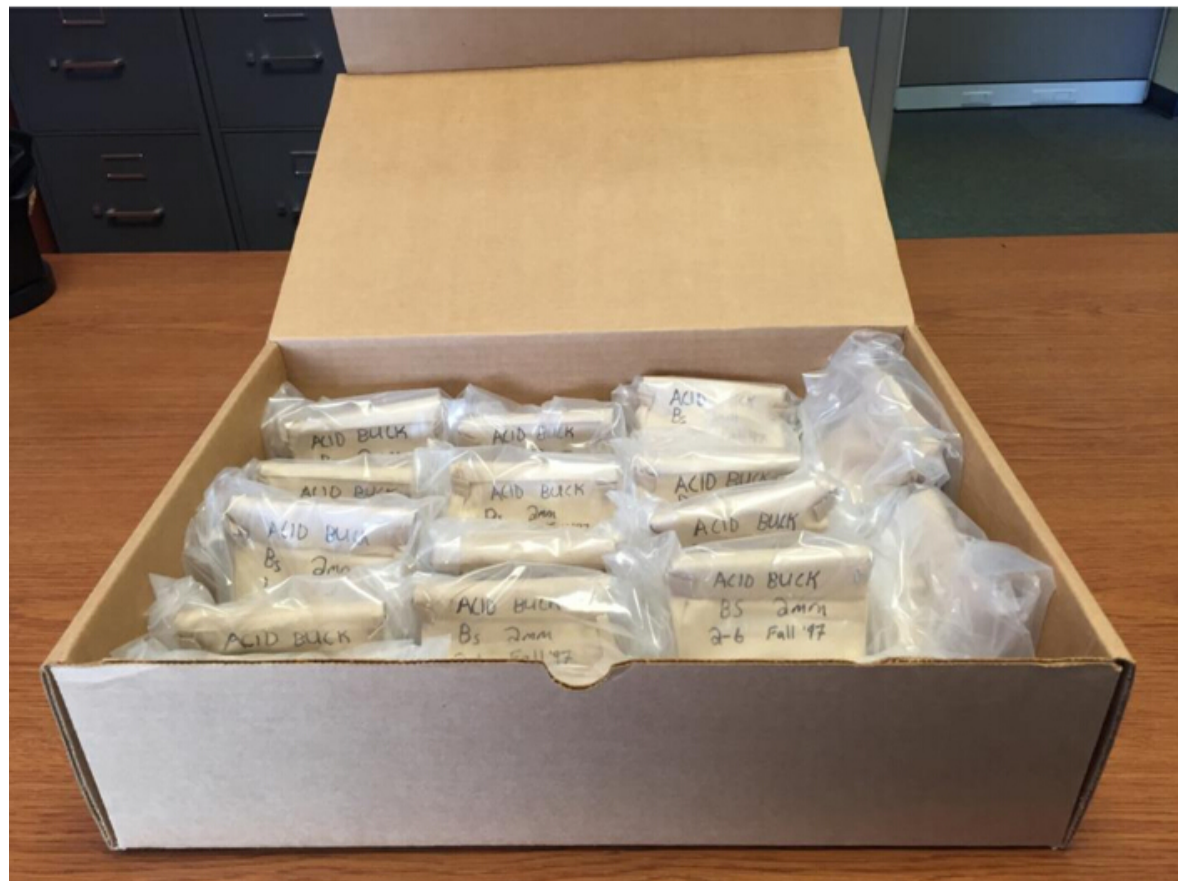

Figure 6: Soil samples packaged for archiving. Internal packaging of archived soil samples. Please click here to view a larger version of this figure.

4. Store the bags in cardboard storage containers configured to the available shelving (such as the method shown in Figure 7. Label the box with information on the samples contained within to enable samples to be located efficiently. Keep the archive room at a stable temperature. 


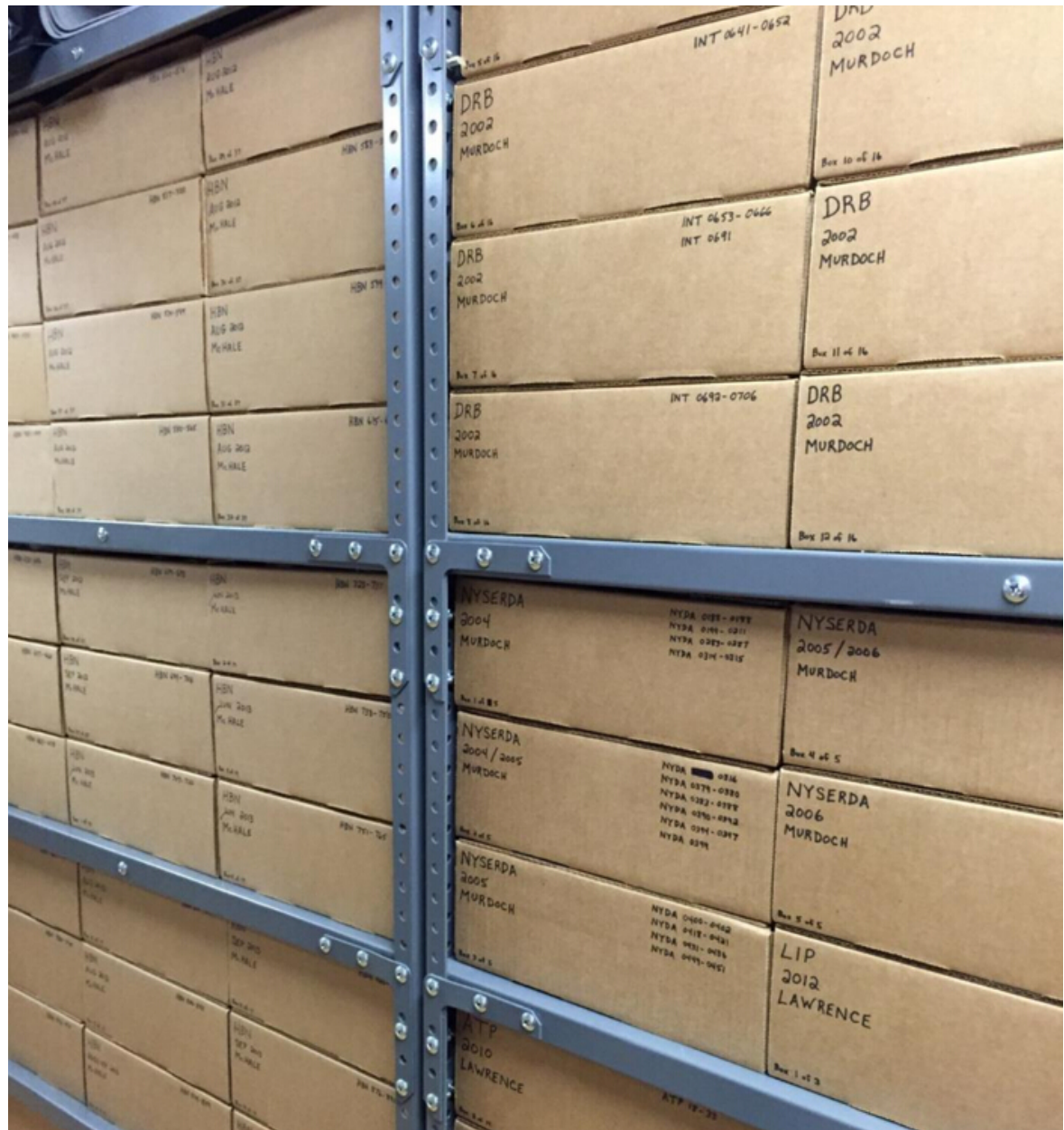

Figure 7: Exampling or archived shelving. Space-efficient shelving of archived soil samples. Please click here to view a larger version of this figure.

5. Store information on each archived sample in a digital database that is routinely backed up. Include (1) sample identification, (2) each date that the sample was analyzed, (3) the laboratory in which the sample was analyzed, (4) the analyses done on each date, (5) the mass of sample remaining (update this each time that a portion of the sample is removed for analysis), and (6) the name of the institution with custodial responsibility for the archived samples.

\section{Verifying Consistency of Chemical Analyses Over Time}

1. Reanalyze a minimum of twelve archived samples from each horizon or depth increment along with the analyses of the newly collected samples.

2. Run a two tailed t-test (or Mann-Whitney rank sum test if data normality is disproven) to determine if chemical analysis results differed significantly $(P<0.10)$ between the previous analysis and the current reanalysis.

NOTE: If a significant difference (or a clear bias that is not statistically significant) is observed, then the relationship between the original data and the reanalysis data should be evaluated. If most of the variability $\left(R^{2}>0.9\right)$ can be explained by this relationship, then it can be used to adjust the data to remove bias. However, if the $R^{2}<0.9$, the remainder of the archived samples should be rerun to ensure that there is no analytical bias when comparing data from the previous sampling results and results obtained from the newly collected samples.

\section{Representative Results}

Data collected in the study of Lawrence et al. ${ }^{9}$ can be used to demonstrate the effect of sampling replication on statistical power for detecting change in Oa horizon samples from 12 pits in a red spruce (Picea rubens) forest in eastern ME. More information on this study site (referred to as Kossuth) is available in Lawrence et al. ${ }^{9}$. The soil (classified as a Spodosol) had a relatively thin Oa horizon (average thickness equaled $2.5 \mathrm{~cm}$ and $3.7 \mathrm{~cm}$ in 1992-93 and 2004, respectively) that overlaid an E horizon with an abrupt boundary. With a sample size of 12 , significant changes $(P<0.05)$ between samples collected in 1992-93 and 2004 were detected in measurements of $\mathrm{pH}$, organic $\mathrm{C}$, and exchangeable calcium (Ca), sodium ( $\mathrm{Na}$ ) and aluminum (Al), whereas no change was observed for exchangeable magnesium (Mg) (Table 1). When 8 of the 12 samples were randomly selected for statistical analysis, significant differences $(P<0.001)$ were observed for exchangeable $\mathrm{Na}$ and $\mathrm{Al}$, and at the $\mathrm{P}<0.10$ level for organic $\mathrm{C}$. With 4 of 12 samples randomly selected, significant differences were only observed for exchangeable $\mathrm{Al}$ and $\mathrm{Na}$ at the $\mathrm{P} \leq 0.05$ level. 


\begin{tabular}{|c|c|c|c|}
\hline Kossuth, ME & Oa Horizon & \multicolumn{2}{|c|}{ 2-tailed T test } \\
\hline $\mathrm{n}$ & Measurement & $\mathrm{p}$ & power at $p<0.05$ \\
\hline \multirow{6}{*}{12} & $\mathrm{pH}$ in $\mathrm{CaCl}_{2}$ & 0.004 & 0.87 \\
\hline & $\mathrm{C}$ & 0.033 & 0.46 \\
\hline & Exch. Ca & 0.008 & 0.79 \\
\hline & Exch. $\mathrm{Na}$ & $<0.001$ & 1.00 \\
\hline & Exch. Al & $<0.001$ & 0.97 \\
\hline & Exch. Mg & 0.161 & 0.16 \\
\hline \multirow{6}{*}{8} & $\mathrm{pH}$ in $\mathrm{CaCl}_{2}$ & 0.111 & 0.36 \\
\hline & $\mathrm{C}$ & 0.063 & 0.47 \\
\hline & Exch. Ca & 0.115 & 0.35 \\
\hline & Exch. Na & $<0.001$ & 1.00 \\
\hline & Exch. Al & $<0.001$ & 0.79 \\
\hline & Exch. Mg & 0.180 & 0.26 \\
\hline \multirow{6}{*}{4} & $\mathrm{pH}$ in $\mathrm{CaCl}_{2}$ & 0.49 & 0.96 \\
\hline & $\mathrm{C}$ & 0.271 & 0.18 \\
\hline & Exch. Ca & 0.237 & 0.20 \\
\hline & Exch. Na & 0.013 & 0.70 \\
\hline & Exch. Al & 0.050 & 0.54 \\
\hline & Exch. Mg & 0.246 & 0.19 \\
\hline
\end{tabular}

Table 1: Sample size effects. Statistical results of using sample sizes of 12,8 and 4 to detect significant differences in chemical measurements of soil samples collected 10 to 11 years apart. $\mathrm{P}$ values considered statistically significant are shown in red italics.

Data from Oa horizons and the upper $10 \mathrm{~cm}$ of B horizons collected in the North and South Tributary watersheds of Buck Creek (western Adirondack region of New York) provide examples of the value of archived soil in reducing uncertainly when comparing data from different time periods. Of the 55 samples collected, analyzed, and archived in 1997-2000, 15 were randomly selected for reanalysis in 2013-14. Analyses in both time periods were done in the laboratory of the U.S. Geological Survey New York Water Science Center, Troy, NY, following the same SOP. Values for exchangeable $\mathrm{Ca}$ in the original and reanalysis of $15 \mathrm{Oa}$ horizon samples showed no difference $(P>0.10)$ for exchangeable Ca concentrations (Figure 8a). Plotting against the 1:1 line also showed little or no bias and the $\mathrm{R}^{2}$ value indicated little unexplained variation. The lack of a difference between original data and data from reanalysis after storage indicates that neither analytical bias nor storage effects during 14-16 years caused erroneous differences in the Ca data. On this basis, reanalysis of the additional 40 Oa samples collected in 1997-98 for exchangeable $\mathrm{Ca}$ concentrations was determined to be unnecessary. 

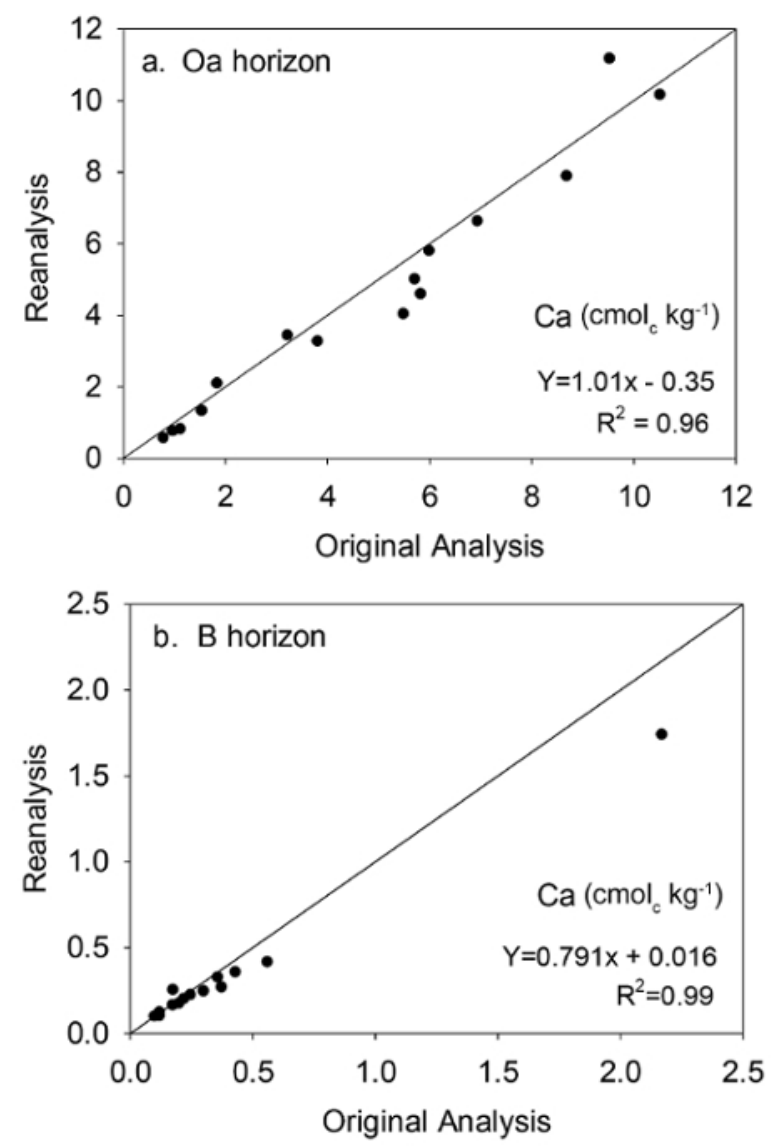

Figure 8: Reanalysis results for $\mathbf{C a}$. The relationship between exchangeable Ca measurements in the Oa horizon (a), and the upper $10 \mathrm{~cm}$ of the B horizon (b), made in 1997-2000 (original analysis) and measurements of the archived samples reanalyzed in 2013-2014 (reanalysis). The $1: 1$ line is shown on the plot. The equation represents the best-fit line determined by linear regression. Please click here to view a larger version of this figure.

A different result was obtained when archived soils were reanalyzed for exchangeable Ca in B horizons (Figure 8b), also using the same SOP. A significant difference $(P<0.10)$ was obtained between the original analysis (mean $=0.40 \mathrm{cmol} / \mathrm{cg}$ ) and reanalysis $($ mean $=0.33 \mathrm{cmol} / \mathrm{cg}$ ), although linear regression showed a highly significant linear relationship between the two data sets $\left(P<0.001 ; R^{2}=0.99\right)$. With this strong relationship, the regression model was used to adjust the original values of the 40 samples not reanalyzed to remove bias with respect to the newly collected and analyzed samples.

A change in the SOP for determining exchangeable Al concentrations resulted in differing results between the original analysis in which Al was measured by titration ${ }^{15}$ and the reanalysis in which Al was measured by inductively coupled plasma (ICP) following Blume et al. ${ }^{14}$. Comparison of exchangeable Al measurements of 15 Oa horizon samples (Figure 9a) between original values (mean $=11.5 \mathrm{cmol} / \mathrm{kg}$ ) and reanalysis $\left(\right.$ mean $\left.=7.8 \mathrm{cmol}_{\mathrm{C}} / \mathrm{kg}\right)$ revealed a strong linear relationship $\left(P<0.001 ; \mathrm{R}^{2}=0.96\right)$ and significant bias $(P<0.05)$. As was done for $B$ horizon Ca concentrations, the regression model was used to adjust the original values of the 40 samples not reanalyzed to remove analytical bias. 

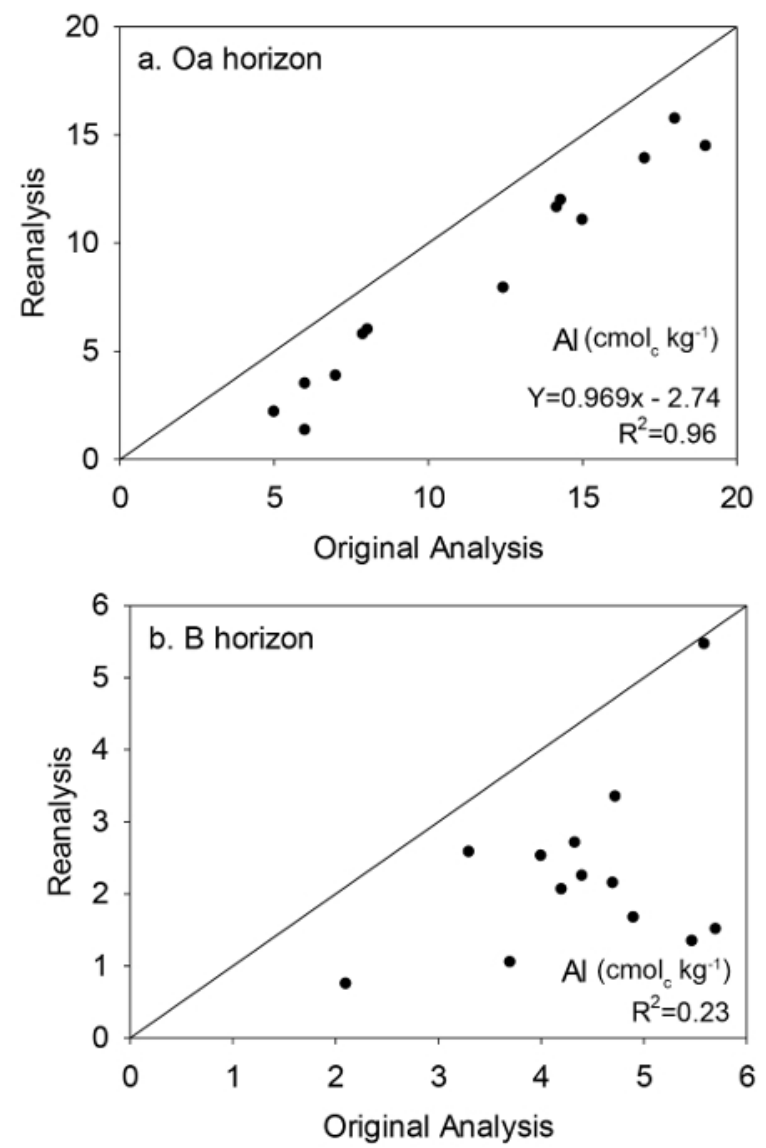

Figure 9: Reanalysis results for Al. The relationship between exchangeable Al measurements in the Oa horizon (a), and the upper $10 \mathrm{~cm}$ of the B horizon (b), made in 1997-2000 (original analysis) and measurements of the archived samples reanalyzed in 2013-2014 (reanalysis). The $1: 1$ line is shown on the plot. The equation represents the best-fit line determined by linear regression. Please click here to view a larger version of this figure.

Original and reanalyzed data for exchangeable $\mathrm{Al}$ in the $\mathrm{B}$ horizon were also significantly different $(\mathrm{P}<0.001)$ and linear regression indicated a significant relationship between the two data sets $(P<0.10)$. In contrast to the Oa horizon Al data, the relationship was weak $(F i g u r e ~ 9 b)$ and the regression model could only account for a small fraction of the variability $\left(R^{2}=0.23\right)$. Because the model could not be used to remove the bias, all of the samples collected and analyzed in 1997-2000 needed to be reanalyzed with the recently collected samples.

A change in analysis method may result in a bias in the data so testing must be done to verify that the data is unbiased. For example, results of archived mineral soils collected at the Turkey Lake Watershed, Ontario, Canada, in 1986 and reanalyzed in $2005{ }^{10}$ are presented in Figure 10. The analysis showed that the two methods produced unbiased data with little unexplained variability (Figure 10). The original analysis was done using the Walkley-Black wet digestion method and the archived samples were analyzed by combustion analyzer. In this case, the comparison between results of the original analysis and analysis of archived samples demonstrated that the data produced by the two methods were directly comparable.

The examples shown in Figures 8-10 demonstrate that the use of consistent analysis methods does not eliminate the possibility of unbiased data, but also shows that a method change does not necessary result in bias. These conclusions emphasize the importance of archived samples to reduce the uncertainty of results by controlling for analytical bias. 


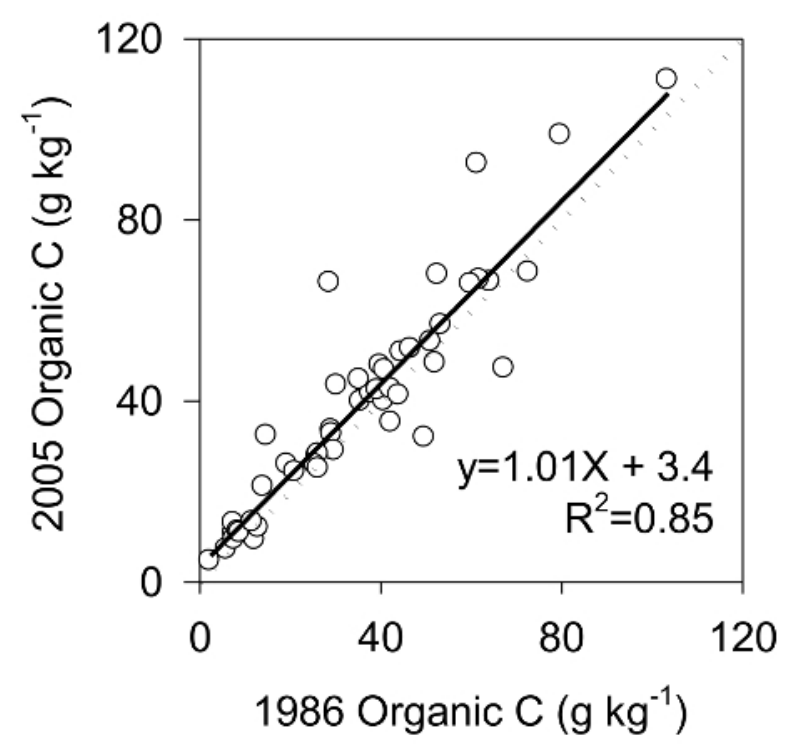

Figure 10: Reanalysis results for C. The relationship between organic C measurements of mineral soils made in 1986 (original analysis) and measurements of archived samples analyzed in 2005. The dotted line is the 1:1 line; the solid line is the linear regression describing the relationship between initial and archived analysis. Please click here to view a larger version of this figure.

Studies that have demonstrated the value of soil monitoring to detect soil changes at individual sites or watersheds are growing, and recently, soil monitoring has been applied to assess effects of acidic deposition decreases in a large regional study ${ }^{14}$. At all of these sites, acidic deposition had decreased over the past three decades, although the acidic deposition levels and rate of decrease varied among sites. A large number of changes were identified in that study, which were generally consistent across the large study region, over differing time periods, using varying resampling designs (Table 2). By linking multiple resampling studies, responses of forest soils to changes in a major environmental driver were identified over an extensive region (Figure 11). The study of Lawrence et al. ${ }^{5}$ demonstrated that results of soil resampling studies with differing designs can be aggregated to address broad regional problems.

Two-tailed T test, unless normality is disproven or unequal variance, then Mann

Whitney rank-sum test

\begin{tabular}{|c|c|c|c|c|c|c|c|c|c|}
\hline & \multirow[b]{2}{*}{$n$} & \multicolumn{2}{|c|}{ Calcmok ky s $\left.^{4}\right)$} & \multicolumn{2}{|c|}{ Na $\left(\right.$ comalic $\left.\mathrm{kg}^{4}\right)$} & \multicolumn{2}{|c|}{$\mathrm{pH}$} & \multicolumn{2}{|c|}{ Al (cmolc kgt) } \\
\hline & & 0 & B & 0 & в & 0 & в & 0 & в \\
\hline BB-TMT, CF, 1998-166 & 8 & $3,432, \mathrm{~ns}$ & a.19-024: is & a.22.031: 15 & a.07-009: is & $3.62 .3 .83 ; 1 \mathrm{15}$ & 4.16-4.44: $P<0.015$ & 10.8.9.1: as & $7.0 .7 .1 ; 1 \mathrm{~ns}$ \\
\hline BB-TMT, $, A T V, 1998-06$ & 8 & $11-6.60 \mathrm{as}$ & 0.81-0.35; $\mathrm{ns}$ & a.4015; $\mathrm{ns}$ & $006-006 ;, 1 \mathrm{~ns}$ & $400-3.96 ; \mathrm{ns}$ & 4.73.4.37; is & 3.460 ns & $5.673 \times \mathrm{P}<0.05$ \\
\hline BB-RFF, CF, 1998-2006 & 8 & 61-58: is & $0.31-0.14 ; P<0.10$ & 27-0.33; ns & ans-a09; ns & $3.62-3.61 ; \mathrm{ms}$ & 4.094.28; is & 7.3-1.1; $\mathbf{P}<005$ & $81-6\} ; n s$ \\
\hline BB-RFF, $A \mathrm{NW} ; 1998.06$ & 8 & 9.7-10.4; is & $0.48 .082 ; 1 \mathrm{~ns}$ & a.17-020; ns & $0.077-0.061 ; \% \mathrm{~s}$ & $4.004 .15 ; P<0.10$ & $4.30-4.49 ; P<0.05$ & 4.2.1. $\mathrm{p} p<0.05$ & $62.59,1 \mathrm{ss}$ \\
\hline Duschessy, QC & $\frac{4}{16}$ & 1.98, , 15 & $2034: \mathrm{ms}$ & $0.4000 ;: P<0.05$ & Q.040-0.033; $:$ s & 3.53-3.89; $P<0.01$ & $4.28 .4 .71 ; P<0.01$ & $23-22 \mathrm{~ns}$ & 6.3.-.1:115 \\
\hline Kessuch, ME & 12 & $6.3-99, \mathrm{P}<00 \mathrm{P}$ & a.15-a10, ns & $0.35-a .13 ; P<0.01$ & $006-0003 ; P<0.01$ & $287 .-3.01 ; P<0.015$ & 4.15.4.02: $\mathrm{ns}$ & $6446<P<005$ & 4.43.4. $\mathrm{p}<0.01$ \\
\hline Houland ME & 12 & 9.5-92:11 & a.10-2:2; $\mathrm{ns}$ & a.37-0.28; $P<0.015$ & $a .05-0.02 ; P<0.01$ & $277-280 ;, \mathrm{s}$ & 4.13.4.27; 15 & 7.2.4. $\mathrm{P}<001$ & $29-22$ us \\
\hline Cranford Notch NH & 12 & $62.60 \%, 1 \mathrm{~s}$ & $0.170 .19 ; \mathrm{ns}$ & $0.38-0.13 ; P<0.01$ & $0.05-002 ; P<0.01$ & $2.62-298: P<0.01$ & 3.91-..83; $\mathrm{ns}$ & 80,$62 ;: P<001$ & $3.6 .38 \mathrm{~ns}$ \\
\hline Barristl, NH & 12 & $9.581: \mathrm{us}$ & $0.10 .004: P<0.015$ & a.27-0.11:P<0.91 & $0.04-0002 ; P<0.01$ & $263-289 ; P<0.01$ & $3.93-3.94 ; \mathrm{ns}$ & $7.547, \mathrm{P}<0.01$ & $29-26 \mathrm{ss}$ \\
\hline Skepens River, VT, afF & 12 & $18-15 ;=\mathrm{s}$ & $041.054 ; 1 \mathrm{Is}$ & a.19-ans; $P<$ <.0.15 & a.073-0.015; $\mathbf{P}<0.01$ & $275.3 .03 ; \mathbf{P}<0.01$ & 3.95-3.81: is & $3.629,1 \mathrm{ss}$ & 4.3-24. $\mathrm{P}<0.01$ \\
\hline Grocten, VT & 12 & 12.7-11.6; ns & all-ans: $\mathrm{ns}$ & $0.28-0.10, P<0.01$ & $0.04-002: P<0.01$ & $287-3.06 ; P<0.10$ & 4.46-4.33: $\mathrm{ns}$ & $5.8-35 ; \mathrm{P}<001$ & 1.3.1.4.115 \\
\hline Back Crock, NY,,$A W$ & 27 & $7.960 .1 \mathrm{Bs}$ & $0.340 .26 ; \mathrm{ns}$ & 0.12-a.0s5: $P<0.01$ & 0.047-0.018: $\mathrm{P}<0.91$ & 3.17-298: $\mathrm{ns}$ & 3.80-3.7.74; 17s & $60.32: P<0.01$ & $2439, \mathrm{P}<0.01$ \\
\hline Baxk Crovk, NY,MFF & 28 & $7.681 ; \mathrm{ns}$ & Q.38-a.41:ns & Q14-0.042; $P<0.01$ & $0.028-0.025 ; P<0.01$ & $209.274: \mathrm{ms}$ & $\begin{array}{l}3.35 \text { to } 3.53, \mathrm{P}< \\
0.05\end{array}$ & 0.08 & $3.3-8 \Leftrightarrow P<0.01$ \\
\hline Big Moose Lake, NY & 12 & $5.8 .7 .1 ; \mathrm{ns}$ & a21-021; $\mathrm{ns}$ & $0.27 .0 .11 ; P<0.01$ & $a$ ass-a.02; $P<0.01$ & $256-2.38: P<0.01$ & 3.58-3.34: 15 & $7.6 .85 ; 1 \mathrm{us}$ & $3.6-64, \mathrm{P}<0.01$ \\
\hline Little Manganet Lake, ON & 5 & - & ar1-020: $P<0.05$ & - & ans_aol: $P<0.01$ & $\ldots$ & $4.22 .451 ; P<0.01$ & 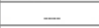 & $20.11: \mathbf{P}<0<10$ \\
\hline Craighanst & 5 & - & 1.1-0.)6, as & - & a.02_-a.01; $\mathrm{ns}$ & $\ldots$ & 4.78-5.17; $P<0.05$ & - & $0.35 .006 ;$, ns \\
\hline Subum, ON & 5 & - & 13.6-6-14.0.: $\mathrm{ns}$ & - & $0.03-0.02 ; p<0.05$ & $\ldots$ & $646-7.10 ; P<0.010$ & - & Below RL. \\
\hline Turiky Lales, $O N$ & 5 & - & $3.8-1.5 ; \mathrm{ns}$ & - & $0.0540 .027 ; P<0.01$ & $\ldots$ & 4.45.4.34:15 & - & $1.622 \mathrm{~ns}$ \\
\hline Kirstund Lake, ON & 5 & 14.2-12.5; $\mathrm{ns}$ & $028-021 ; \mathrm{ms}$ & $0.13-0.11 ; \mathrm{m}$ & $0.033-0.019 ;: P<0.01$ & 3.12-.3.82; $P<0.01$ & 4.16-4.64; $P<0.01$ & $3.3-0 \geq, P<00 t$ & \\
\hline Flane Lake, ON & $s$ & & a.15-a09: ns & $0.20 .0 .13 ; P<0.01$ & a.041-0.018: $P<0.91$ & $3.48-3.23 ; \mathrm{P}<0.05$ & 4.73.5.32; $\mathrm{P}<0.01$ & $61-1,7 ; P<001$ & $\begin{array}{l}a 201 \\
a 01 \\
\end{array}$ \\
\hline Wama, ON & 5 & $\begin{array}{l}7.2 .25,3 ; P< \\
0.01\end{array}$ & a.17-0.12; ns & a.4.0.13; ns & $0.019-0.016 ; c_{5}$ & $3.07-3.98 ; P<0.01$ & $4.37-4.78 ; P<0.01$ & $4604, P<001$ & $\mathrm{~ms}$ \\
\hline Dryder, on & 5 & 2.5-13.5; $\mathrm{ns}$ & a.s-a21:ns & $0.17-0.12 ; \mathbf{P}<0.015$ & $0.0240 .015 ; P<0.01$ & 3.23-3.34; $\mathrm{P}<0.05$ & $4.46-501 ; P<0.05$ & $35-1.6 \mathrm{P}<0.10$ & $\begin{array}{l}a, 44-0.17 ; P<< \\
a .01\end{array}$ \\
\hline
\end{tabular}

Table 2: Examples of resampling results. Mean values (initial - final) and results of tests (T-tests or Mann-Whitney tests) for differences between initial and final measurements for $\mathrm{O}$, and upper $\mathrm{B}$ horizons for soil investigations in the northeastern US and Eastern Canada (locations shown in Figure 11). $P$ values $>0.10$ are indicated as ns (not significant). Analyses with $P<0.1$ are shown in yellow to indicate significant differences observed in these measurements for sites located across the northeastern U.S. and eastern Canada. Boxes with dashed lines indicate no data. BB stands for Bear Brook, ME; TMT stands for BB sites that received experimental additions of $\left(\mathrm{NH}_{4}\right)_{2} \mathrm{SO}_{4}$ annually. $\mathrm{REF}$ refers to untreated sites at BB. Some sites had different study units based on forest type. CF stands for northern conifer stands; HW northern hardwood stands; MF stands for mixed conifer-hardwood stands. Please click here to view a larger version of this table. 


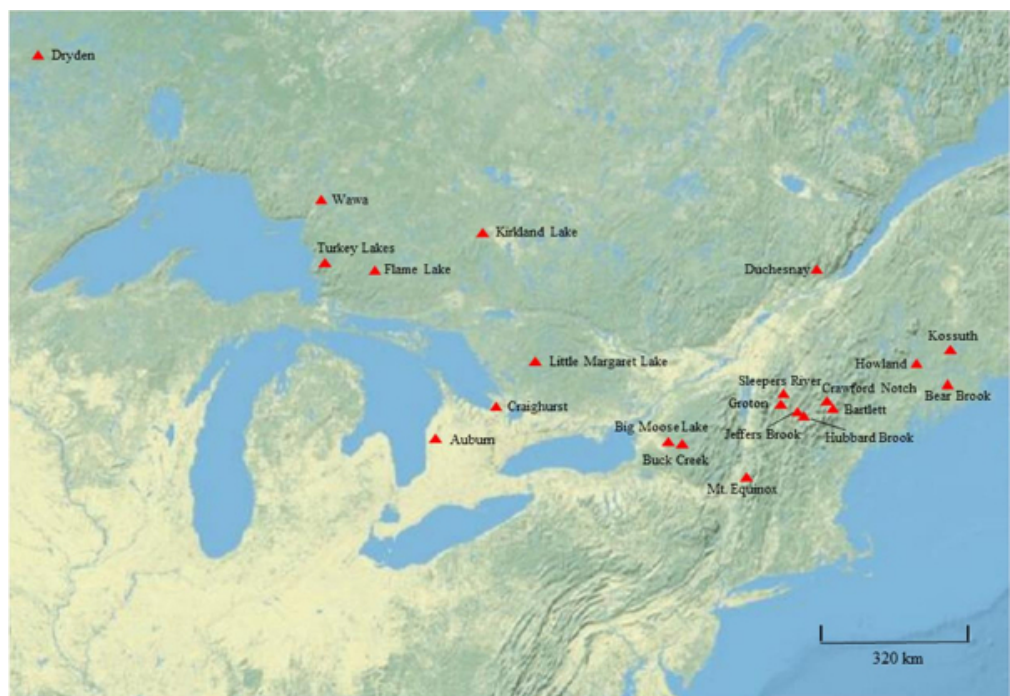

Figure 11: Map of resampling sites. Locations of soil resampling investigations in eastern Canada and the northeastern United States presented in Table 2. Please click here to view a larger version of this figure.

\section{Discussion}

Selection of which horizons or depth increments to sample is guided by the objectives of the monitoring, but is ultimately dependent upon the characteristics of the soil. The decision of where and how to sample the profile is therefore a critical step in soil monitoring. For example, the Spodosol shown in Figure 12 has a forest floor with a boundary between the Oe (moderately decomposed organic matter) and Oa (black humified organic matter) that is abrupt and the two horizons are sufficiently thick to enable them to be sampled separately. This profile also has a well-defined $\mathrm{E}$ horizon with an abrupt boundary separating the organic Oa horizon from the mineral E horizon. These colorful horizons with abrupt boundaries enable collection of the same horizon material to be consistently repeated, making these horizons excellent candidates for soil monitoring. If the boundary between the mineral and organic layers is not clearly seen or is gradual relative to the horizon thickness, repeated sampling of layers directly above and below this interface will likely include varying amounts of soil from the adjacent layers. This characteristic adds uncontrolled variation and would therefore make these horizons less desirable for repeated sampling.

In some instances, sampling by depth interval can provide a consistent sampling approach in soils where certain horizons are mixed or intermingled, if this mixing is a consistent feature of the soils being monitored. In Figure 12, the upper $10 \mathrm{~cm}$ of the $\mathrm{B}$ horizon has an abrupt boundary with the $\mathrm{E}$ horizon, but color variation suggests the presence of Bh and Bhs horizons that are intermixed. In this situation, sampling the upper $10 \mathrm{~cm}$ of the B horizon would be the most repeatable collection method. This approach has proven successful in Spodosols such as shown in Figure $12^{7}$.

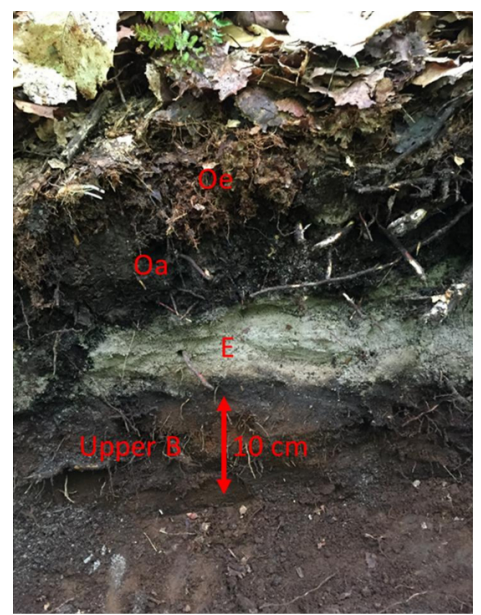

Figure 12: Spodosol profile. A Spodosol horizon from the Adirondack region of New York showing the distinctive $E$ horizon that separates the forest floor (Oa and Oe horizon) from the B horizon. Please click here to view a larger version of this figure.

Full profile descriptions are extremely useful in reducing the chance of sampling bias and interpreting the data, but collecting this information is time consuming and could limit the time available for available sampling replication, depending upon project resources and available field time. An alternative to full profile descriptions of each pit would be to make a full description of a primary pit (with photo), then limit descriptions for replicate pits to measurements of horizon thickness along with profile photographs. This information would be sufficient to verify that resampling 
was done in the same soil in a manner consistent with the prior sampling. High quality images are extremely valuable for maintaining sampling consistency when resampling profiles to determine chemical changes over time.

Assessment of potential bias from sampling inconsistencies can be evaluated through comparisons of measurements among horizons. For example, lower concentrations of organic carbon were observed in the Oa horizon in a second sampling than in the initial sampling conducted 10-12 years earlier ${ }^{9}$. This might have resulted from a sampling bias-more of the underlying mineral $\mathrm{E}$ horizon may have been collected in the second sampling than in the first sampling. This would lower the organic carbon concentration, and likely lower the exchangeable Ca concentration because $\mathrm{E}$ horizon $\mathrm{Ca}$ concentrations in the soil being studied were at least an order of magnitude lower in than in the Oa horizon. The lack of a decrease in the E-horizon Ca concentrations observed in this study provides evidence to support the interpretation that lower organic $\mathrm{C}$ concentrations in the second sampling were not a result of sampling bias. This type of comparison among horizons provides valuable information for evaluating sampling consistency. Therefore sampling additional horizons not specifically needed for project objectives is warranted to help reduce uncertainly in results.

Reanalysis of archived soil samples is a key practice in reducing uncertainty. However, archiving of soils requires resources to manage the archive and storage space that can be difficult to acquire on a permanent basis. Therefore, the mass of archived soil must be used judiciously. Reanalyzing all archived soil samples for a particular resampling study is generally the most effective approach for reducing chemical analysis uncertainty, but selective reanalysis of archived samples, where possible, will help to conserve the irreplaceable soil for future uses. Reanalysis of all archived samples should not be done unless necessary. A variety of methods for archiving soil are currently in use and have been shown to be effective. The method and materials recommended in this article are based on the experience of curators of the New York State Museum, who have found that this highly space-efficient packaging design protects the sample in unbreakable, water resistant, easily labeled materials, which are stable for many decades.

Protecting archived soil samples is a key step in soil monitoring because it not only enables analytical consistency between samplings, it also provides the opportunity for future analysis with methods that have not yet been developed. Furthermore, the archived samples can provide information to address new questions as they will undoubtedly arise in the future. Had archived soil samples predating acid rain been available, effects of this disturbance on soils would have been identified within years rather than decades after its discovery. Instead, pre-acid rain soil chemistry remains uncertain as we now monitor the recovery of soils from declining acid rain levels.

Soil monitoring is somewhat limited by the time-frame over which change can be detected (generally 5 years or more), and with a reliance on destructive sampling, the sampling area needed for monitoring increases over time. Nevertheless, without soil monitoring, soil changes must be inferred from indirect approaches, such as chronosequences (space for time substitution), watershed mass balances, dendrochemistry, short-term manipulations and modeling. These approaches provide coarse estimates of soil change, and all require assumptions that increase uncertainty that can be best reduced through direct measurements of soil through time. The procedures of repeated soil sampling can also be applied to long-term controlled manipulation experiments, such as the watershed Ca-addition experiment at the Hubbard Brook Experimental Forest, $\mathrm{NH}$, lasting more than 12 years ${ }^{16}$ and the Calhoun, SC, long-term soil experiment lasting more than 50 years ${ }^{2}$.

\section{Disclosures}

The authors acknowledge the support of the New York State Energy Research and Development Authority, the Northeastern States Research Cooperative, and the Vermont Long-Term Soil Monitoring Project. We also thank M.B. Adams, USDA Forest Service for her helpful manuscript review.

\section{Acknowledgements}

The authors have nothing to disclose.

\section{References}

1. Walker, T. W., \& Syers, J. K. The fate of phosphorus during pedogenesis. Geoderma. 15, 1-19 (1976)

2. Lawrence, G. B. et al. Measuring environmental change in forest ecosystems by repeated soil sampling: a North American perspective. J. Environ. Qual. 42, 623-639 (2013).

3. Lawrence, G. B., \& Bailey, S. W. Workshop establishes the Northeastern Soil Monitoring Cooperative EOS. 23, 247 (2007).

4. Desaules, A. Measurement instability and temporal bias in chemical soil monitoring: sources and control measures. Environ. Monit. Assess. 184, 487-502 (2012).

5. Lawrence, G. B. et al. Declining acidic deposition begins reversal of forest-soil acidification in the Northeastern U.S. and Eastern Canada. Environ. Sci. Technol. 49, 13103-13111 (2015).

6. Schoeneberger, P. J., Wysocki, D. A., Benham, E. C., \& Staff, S. S. Field book for describing and sampling soils, Version 3.0. Natural Resources Conservation Service, National Soil Survey Center, Lincoln, NE., (2012).

7. Soil Science Staff, Keys to Soil Taxonomy. $12^{\text {th }}$ ed. USDA Natural Resources Conservation Service. Washington, D.C. (2014).

8. Ross, D. S. et al. Inter-laboratory variation in the chemical analysis of acidic forest soil reference samples from eastern North America. Ecosphere. 6, 73 (2015).

9. Lawrence, G. B. et al. Early indications of soil recovery from acidic deposition in U.S. red spruce forests. Soil Sci. Soc. Am. J. 76, 1407-1417 (2012).

10. Hazlett, P. W., Curry, J. M., \& Weldon, T. P. Assessing decadal change in mineral soil cation chemistry at the Turkey Lakes Watershed. Soil Sci. Soc. Am. J. 75, 287-305 (2011).

11. Bailey, S. W., Horsley, S. B., \& Long, R. P. Thirty years of change in forest soils of the Allegheny Plateau, Pennsylvania. Soil Sci. Soc. Am. J. 69, 681-690 (2005). 
12. Johnson, A. H., Moyer, A. J., Bedison, J. E., Richter, S. L., \& Willig, S. A. Seven decades of calcium depletion in organic horizons of Adirondack forest soils. Soil Sci. Soc. Am. J. 72, 1824-1830 (2008).

13. Ross, D. S., Hales, H. C., Shea-McCarthy, G. C., \& Lanzirotti, A. Sensitivity of manganese oxides: dryng and storage cause reduction. Soil Sci. Soc. Am. J. 65, 736-743 (2001).

14. Blume, L. J. et al. U.S. Environmental Protection Agency, EPA/600/4-90/023. Washington, D.C. (1990).

15. Thomas, G. W. in Agronomy No. 9. (ed A.L. Page) 159-166 ASA, (1982).

16. Johnson, C. E., Driscoll, C. T., Blum, J. D., Fahey, T. J., \& Battles, J. J. Soil chemical dynamics after calcium silicate addition to a northern hardwood forest. Soil Sci. Soc. Am. J. 78, 1458-1468 (2014). 